\title{
Dermal Toxicity Studies of Technical Polychlorinated Biphenyls and Fractions Thereof in Rabbits
}

\author{
J. G. Vos AND R. B. BeEMS \\ Institute of Veterinary Pathology and Institute of Veterinary Pharmacology and Toxicology, \\ University of Utrecht, Biltstraat 172, Utrecht, The Netherlands \\ Received October 5, 1970
}

Dermal Toxicity Studies of Technical Polychlorinated Biphenyls and Fractions Thereof in Rabbits. Vos, J. G., and Befms, R. B. (1971). Toxicol. Appl. Pharmacol. 19, 617-633. A significant difference in toxicity between 3 polychlorinated biphenyl (PCB) preparations was found in a prior study: Clophen A 60 and Phenoclor DP6 showing the highest, Aroclor 1260 the lowest, toxicity (Vos and Koeman, 1970). A subsequent study revealed the presence of tetra- and pentachlorodibenzofuran in Phenoclor and Clophen (Vos et al., 1970). In the present study, application of $118 \mathrm{mg}$ of the 3 PCB's ( 5 times per wk, for 38 days) on the back skin of rabbits also resulted in differences in toxicity.

PCB-induced skin lesions were hyperplasia and hyperkeratosis of the epidermal and follicular epithelium. Histopathology of the liver included centrolobular degeneration, centrolobular liver cell atrophy, focal necrosis, and cytoplasmic hyalin degeneration. Definite hyperplasia and hyperkeratosis of the follicular epithelium of the ear skin were seen after the topical application of fractions of Phenoclor and Clophen eluted from chromatographic columns with $25 \%$ diethylether in hexane. The fraction from Aroclor caused a minimal hyperplasia and hyperkeratosis of the follicular epithelium. PCB-induced kidney lesions were hydropic degeneration of the convoluted tubules and tubular dilatation with the presence of casts. This dilatation was demonstrated also by a significantly increased relative percentage of the diameter which corresponds to the space of Bowman. Moreover, thymus atrophy and lymphopenia were found. Fecal coproporphyrin and protoporphyrin excretion was increased.

Polychlorinated biphenyls (PCB) have been identified in tissues of fish and wildlife in many countries (Jensen, 1966; Holmes et al., 1967; Holden and Marsden, 1967; Koeman et al., 1967; Risebrough et al., 1968; Koeman et al., 1969; Jensen et al., 1969; Duke et al., 1970; Prestt et al., 1970).

PCB preparations are extremely stable, oily fluids with very low aqueous solubility. They are used as lubricants, as heat transfer media, in protective coatings for wood, metal, and concrete, and for many other applications. Which of these applications has contributed to the present environmental contamination has not yet been established.

Inhalation and feeding experiments in rats with $65 \%$ chlorinated PCB resulted in liver injury (Drinker et al., 1937; Bennett et al., 1938). Liver damage and skin lesions have been described after inhalation, ingestion, and application to the skin using rabbits, guinea pigs, and mice (von Wedel et al., 1943). Hydropericardium occasionally accompanied by abdominal edema was found in chicks fed PCB (McCune et al., 1962; Flick 
et al., 1965; Vos and Koeman, 1970). Epithelial and follicular hyperplasia and hyperkeratosis were found after application of PCB on the skin of rabbits (Adams et al., 1941). Subcutaneous injection of $42 \%$ chlorinated $P C B$ in rats, guinea pigs, and rabbits resulted in liver injury and skin lesions, which were essentially those of chloracne (Miller, 1944). Follicular hyperkeratosis is an important feature of the occupational disease known as chloracne, which is characterized by the appearance of papules, comedones, and cysts. It may devejop after exposure to some highly chlorinated aromatic compounds. Examples are chlorinated naphthalenes (Greenburg et al., 1939; Hambrick, 1957; Shelley and Kligman, 1957) and chlorinated phenols (Hofmann, 1957; Bauer et al., 1961 ; Bleiberg et al., 1964). The active compounds in chlorinated phenols have been identified as chlorinated dibenzodioxins (chlorinated diphenylene dioxides) which may appear as contaminants in the synthesis of chlorophenols (Bauer et al., 1961). Liver injury (acute yellow atrophy), whether accompanied by chloracne lesions or not, is also described in people engaged in the manufacture of the chlorinated hydrocarbons (Strauss, 1944; Braun, 1955; Behrbohm, 1959). Also for the PCB's there are early reports of occupational chloracne (Jones and Alden, 1936; Schwartz, 1936). The presentday use of PCB does not seem to have led to this kind of difficulty.

A significant difference in toxicity between 3 samples of commercial PCB preparations was found in a previous study (Vos and Koeman, 1970), despite the marked resemblance of the gas chromatograms and the mass spectra (Koeman et al., 1969). One hundred per cent mortality, centrolobular liver necrosis, and sc and abdominal edema were found only in chicks fed the samples of Clophen A60 and Phenoclor DP6. Hydropericardium was recorded in nearly all chicks fed these PCB's, and was only occasionally seen in chicks fed with Aroclor 1260. Porphyria was found as a general PCB effect (Vos and Koeman, 1970).

The hypothesis that in some technical PCB mixtures toxic factor(s) responsible for the chick edemalike lesions and the liver necrosis were present has been the subject of further work. By means of column fractionation, gas chromatography, and mass spectrometric techniques, tetra- and pentachlorodibenzofuran were identified as the toxic factors in the samples of Clophen A60 and Phenoclor DP6 (Vos et al., 1970).

These results suggest that PCB's contaminated with polychlorodibenzofurans may also produce chloracne and associated lesions when applied to the skin of experimental animals. To test this possibility the present study was undertaken.

\section{METHODS}

The PCB samples, which contain an average of $60 \%$ chlorine, were obtained from Prodelec in France (Phenoclor DP6), Bayer in Germany (Clophen A60 Lot No. 912434) and Monsanto in the United States (Aroclor 1260 Lot No. AK-3).

Adult female New Zealand rabbits, 5 mo old and weighing 2500-3050 g, were used in this study. They received pelleted food (Cunicon 1, Trouw and Co., Amsterdam) and water ad libitum. The animals were distributed at random into 4 groups of 4 animals, and were weighed weekly.

An area of approximately $10 \times 15 \mathrm{~cm}$ on the backs was clipped, the remaining hair was shaved with a shaving powder $(90 \mathrm{~g}$ barium sulfide, $105 \mathrm{~g}$ zinc oxide, and $180 \mathrm{~g}$ starch), and the resulting small skin abrasions were allowed to heal for 3 days. 
The 3 PCB's were dissolved in isopropanol ( $118 \mathrm{mg} \mathrm{PCB} / \mathrm{ml})$. One $\mathrm{ml}$ of PCB solution or of isopropanol as a control was dropped daily, 5 times a wk, on an area of $5 \times 10 \mathrm{~cm}$ by means of a calibrated syringe. In order to minimize eventual ingestion of the PCB, the animals were held for $7 \mathrm{hr}$ in restraining boxes, after which time they were returned to their wire cages ( 2 animals per cage).

In order to study the porphyrogenic action of the PCB preparations in the same rabbits, pooled samples of the feces of the 4 groups were analyzed weekly for coproporphyrin and protoporphyrin contents (Rimington, 1961), using a Beckman spectrophotometer.

The animals which survived the 38-day test period (27 applications of $118 \mathrm{mg}$ PCB) were killed. At necropsy, performed on all animals that died or were killed, a gross pathologic examination was carried out, including macroscopic examination in ultraviolet light using red fluorescence as an indication of porphyria. In order to get information on the fecal excretion of coproporphyrin and protoporphyrin of the individual animal, feces collected from the cecum were analyzed.

Hematologic examination included hemoglobin and hematocrit determinations, leukocyte and differential leukocyte counts. Clinical chemical determinations were made of serum glutamic-oxaloacetic transaminase and glutamic-pyruvic transaminase (Reitman and Frankel, 1957) using a Beckman/Spinco 151 spectrocolorimeter.

The weights of body, liver, kidneys, spleen, heart, and adrenals were recorded. The skin, liver, spleen, kidney, pancreas, ovary, heart, lung, thymus, mesenteric lymph node, stomach, small intestine, cecum, large intestine, and skeletal muscle were fixed in $10 \%$ buffered formalin and embedded in Paraplast. Sections $(7 \mu$ and $2 \mu$ ) were stained with hematoxylin-eosin. For detailed histology, selected sections were stained with Perls, Azan, PAS, Ziehl-Neelsen, Congo red, and thioflavine. Moreover, cryostat sections of formalin-fixed livers and kidneys were stained with Sudan black. Thioflavinestained sections, unstained Paraplast-embedded sections, and unmounted cryostat sections of liver, kidney and small intestine were examined in a fluorescence microscope.

Prompted by the observation of tubular dilatation in the kidneys in previous studies after PCB ingestion (McCune et al., 1962; Vos and Koeman, 1970), measurements were made on random samples of capsules of Bowman and glomeruli in $2-\mu$ kidney sections. Measurcments of onc axis of the greatest diameter of both capsule and glomerulus were made of 25 renal corpuscles in a straight traverse across the cortex of each kidney. The relative percentage of the diameter which corresponds to the space of Bowman, as an index of dilatation of the nephron, was calculated from the measurements of each renal corpuscle.

An additional experiment was made with the chromatographic fraction (column eluted with $25 \%$ diethylether in hexane) of the 3 PCB's, containing tetra- and pentachlorodibenzofuran in the case of Phenoclor DP6 and Clophen A60 (Vos et al., 1970), to determine the dermal toxicity of this fraction. Aliquots of $600 \mathrm{mg}$ of the 3 PCB mixtures were fractionated (Vos et al., 1970). The $25 \%$ diethylether-hexane fractions were evaporated and dissolved in $0.6 \mathrm{ml}$ of ethanol. Four female albino rabbits ( 3 test animals and 1 control), 2 mo of age and weighing 1550-1750 g, were used as the experimental animals. A $0.2-\mathrm{ml}$ portion of the ethanol solution was applied weekly, for $3 \mathrm{wk}$, to an area of $4 \mathrm{~cm}^{2}$ on the inside of the rabbit ear. The opposite ear served as a control. The 

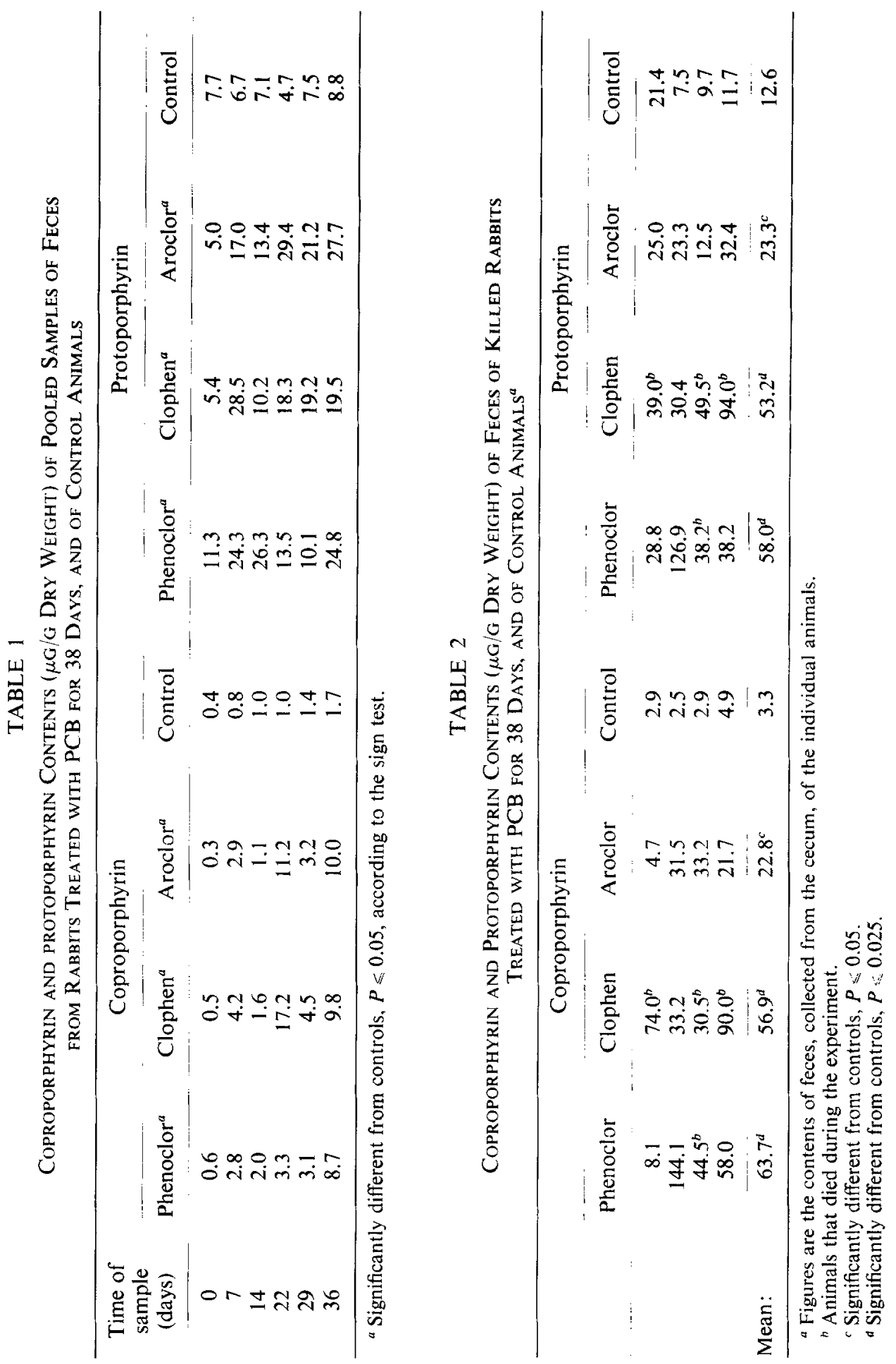
animals were killed after 3 wk. Body and liver weights were recorded. Sections of the ear and the liver were stained with hematoxylin-eosin. Cryostat sections of the livers were also stained with Sudan black.

Statistical significance, on a one-tail significance level, was determined using the Wilcoxon test for 2 unrelated samples (van der Waerden, 1957).

\section{RESULTS}

\section{Experiment with Commercial PCB Preparations in Rabbits}

The skin, especially of the Clophen- and Phenoclor-treated animals, became reddened after 2 days of PCB treatment. This redness was more pronounced after $1 \mathrm{wk}$ of treatment, together with clear desquamation of the external epidermal layers and reduced regrowth of hair. Thickening of the skin and prominent transverse wrinkles of the treated skin developed during the experiment.

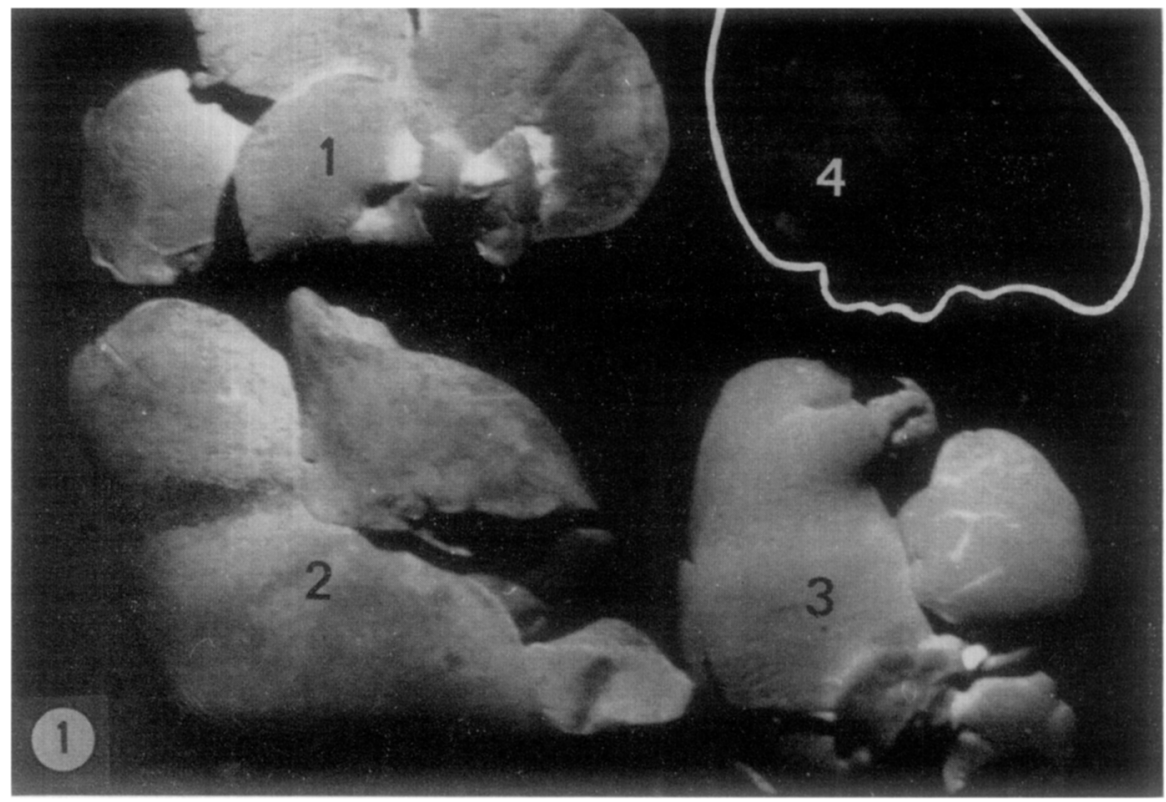

FIG. 1. Fluorescence of porphyrins under ultraviolet light in livers from PCB-treated killed rabbits. I, Aroclor; 2, Clophen; 3, Phenoclor; and 4, control liver.

The results of the spectrophotometric determinations of fecal coproporphyrin and protoporphyrin are given in Table 1.

The test animals showed, in general, a gradual loss of weight. One Phenoclor- and 3 Clophen-treated animals died, with severe weight loss, after 10, 31, 32, and 32 days, respectively.

At necropsy, carried out on all animals, it was found that 1 animal in each of the 3 test groups showed definite edema formation, with fluid in the abdominal and thoracic cavity, subcutis, and pericardium.

All test animals, except for 1 rabbit of the Clophen group that died after 32 days of treatment, showed fluorescence in ultraviolet light. Liver (Fig. 1) and bone fluorescence 

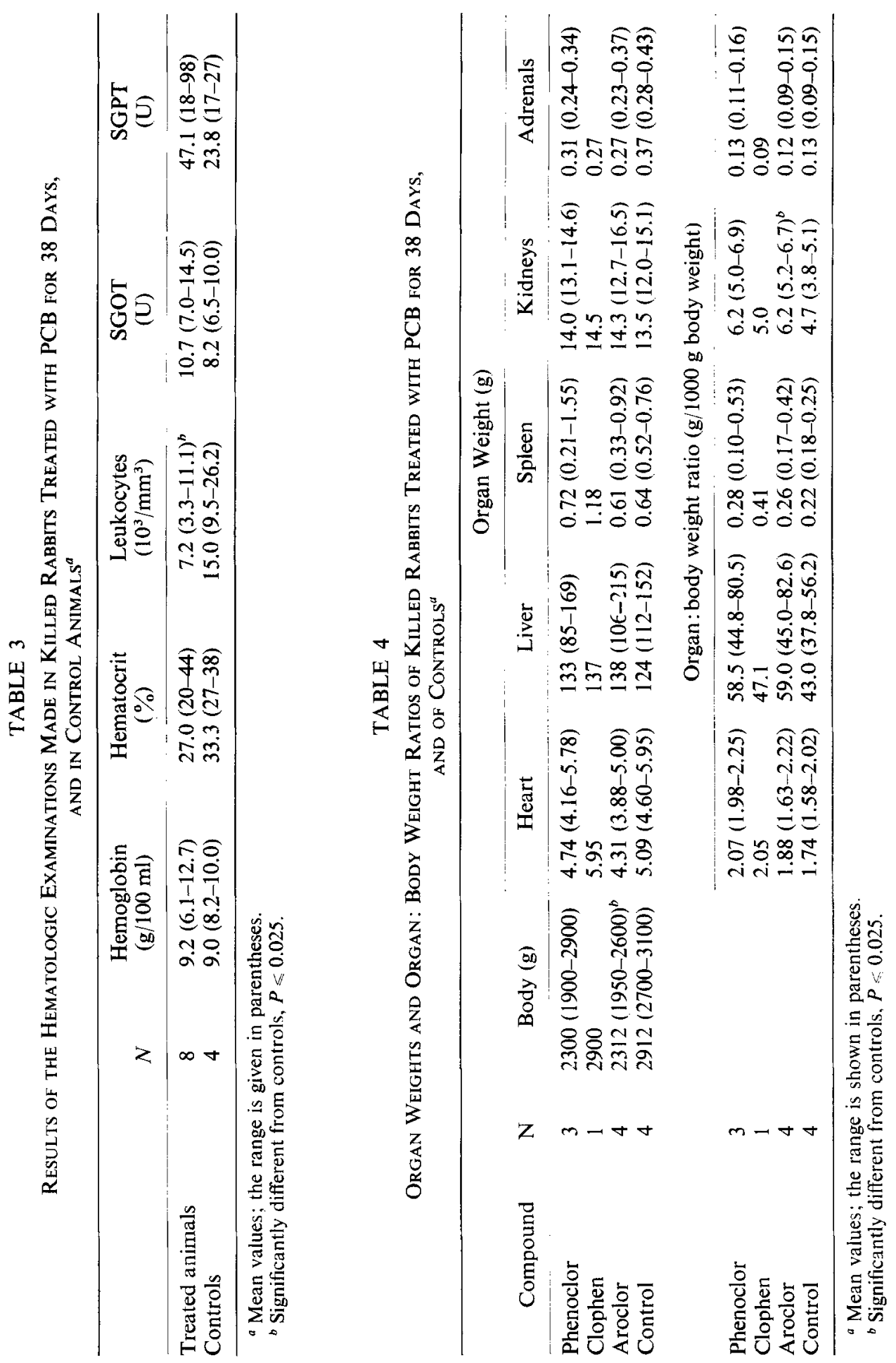
was observed most frequently; fluorescence of incisors, kidneys, small intestine, and subcutis was found in about half of the test animals. There was no fluorescence in the bone marrow. Fluorescent microscopic examination of cryostat sections of the livers revealed that porphyric animals had porphyrin diffusely distributed throughout the whole lobule. Small foci inside parenchymal cells, probably nuclei, revealed an even more intense red fluorescence. Kidney sections showed, when positive, a weak red fluorescence, which was found in the cytoplasm of the tubules in marrow and cortex. Fluorescence of granules (perhaps nuclei) in glomeruli was also noted.
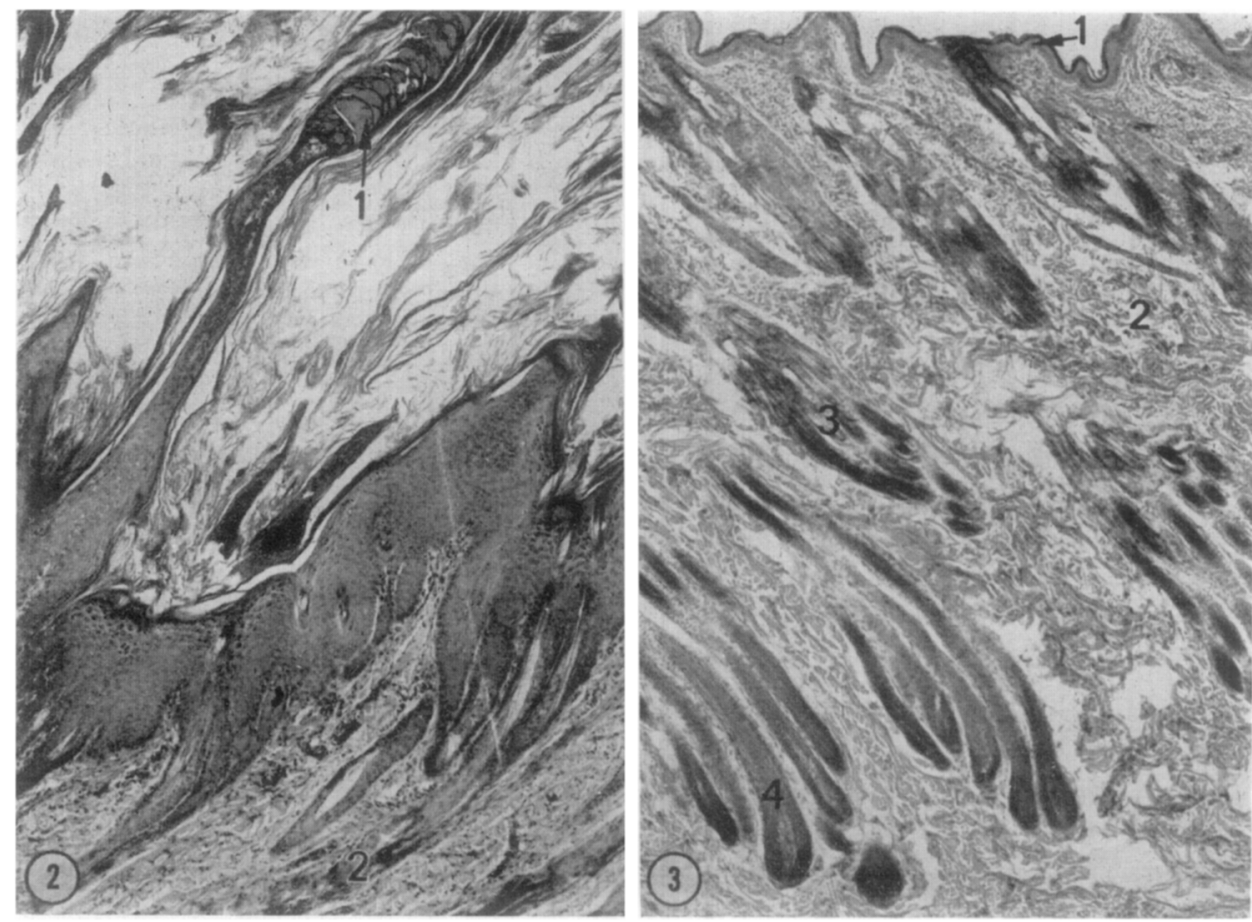

FIG. 2. Back skin of a killed rabbit from the Phenoclor-treated group. Hyperplasia and hyperkeratosis of the epidermal and follicular epithelium. Follicular plugging is prominent. Note the hyalin foci in the cytoplasm of epidermal cells ( 1 ), and the resting (telogen) phase of the hair follicles (2). Hematoxylin and eosin. $>46$.

FIG. 3. Normal skin of back of a control animal treated with the solvent isopropanol showing epidermis at 1 and dermis at 2 . Several groups of hair follicles, cut somewhat tangentially to their long axes, are seen at 3 ; groups of hair bulbs are seen at 4 . Hematoxylin and eosin. $\times 46$.

Coproporphyrin and protoporphyrin contents of feces collected from the cecum at necropsy are given in Table 2 . The degree of excretion was not related to the intensity of porphyrin fluorescence; for example, the Clophen- and Aroclor-treated rabbits with a coproporphyrin excretion of 30.5 and $4.7 \mu \mathrm{g} / \mathrm{g}$ (Table 2), showed, respectively, no fluorescence at all, and fluorescence of liver, bone, incisors, kidneys, small intestine, and subcutis.

The results of the hematologic determinations are given in Table 3. The PCB-treated animals of the 3 groups have been taken together since there were no differences between the groups. The total number of leukocytes was significantly reduced in the test 
animals. Mean SGOT and SGPT values were increased, but the large variation in individual values and the small number of animals made the apparent differences statistically indistinguishable. The differential count of leukocytes was not significantly altered.

Organ weights and organ: body weight ratios, are given in Table 4. A significant decrease in body weight and a significant increase in the relative weight of the kidneys was found in the Aroclor-treated animals. Mean absolute and relative liver weights of the test animals were increased, but the variation was also very high.

At microscopic examination of the skin, thickening of the skin due to hyperplasia and hyperkeratosis of the epidermal epithelium was apparent (Fig. 2). A pronounced hyperplasia and hyperkeratosis of the follicular epithelium was also present, with the formation of comedolike structures (hair follicles which become dilated and filled with a keratinous plug) (Fig. 2). These changes were found, in general, in all treated animals. but the Phenoclor-treated animal which died after 10 days showed less advanced alterations. Follicular changes in the Aroclor group were generally less deep; the hyperplasia and hyperkeratosis were more restricted to the upper part of the hair follicles. Thickening of the surface and follicular epithelium was accompanied by the presence of large quantities of keratohyalin granules in the stratum granulosum. In general, PAS-positive, diastase-resistant hyalin foci were seen in the cytoplasm of epidermal cells, located above the cutis papilla (Fig. 2). Dedifferentiation of the sebaceous gland tissue was found in primarily the Phenoclor and the Clophen groups. Hair follicles in the resting phase (telogen phase) were predominantly seen in the same 2 experimental groups (Fig. 2). The differences in response between Aroclor-treated rabbits on the one hand and the Clophen-and Phenoclor-treated rabbits on the other are quantitative, not qualitative. No differences in response were found between the two latter groups. In control rabbits treated with the solvent isopropanol, these changes did not occur (Fig. 3).

Histopathology of the livers of the treated animals showed a considerable diversity in lesions (Figs. 4 and 5), among them centrolobular degeneration (degenerated cells with nuclear pycnosis, rhexis, and lysis), focal hydropic degeneration (foci of swollen cells with a light cytoplasm that did not stain with Sudan black and PAS, suggesting a pronounced cellular edema), focal necrosis (foci of necrotic cells that were found in various portions of the lobules), centrolobular liver cell atrophy (atrophy of the cytoplasm of liver parenchymal cells in the centrolobular area), cytoplasmic hyalin degeneration (foci of intracellular eosinophilic hyalin material), and pigment in Kupffer and to a lesser degree in parenchymal cells. The pigment stained positive with Ziehl-Neelsen. PAS and Perls and showed a yellow-brownish fluorescence; these are strong indications for ceroid (Porta and Hartroft, 1959). The results of the microscopic examination are given in Table 5. In general, PCB-induced liver lesions were most pronounced in the Clophen group and least in the Aroclor group. Periportal fibrosis was a common finding in the treated animals, but it was not found in the controls. Since some coccidia were found in a bile duct in 1 liver, it is quite possible that the fibrosis has to be considered as a healed coccidiosis. Material positive to Sudan black was seen in some fibrotic portal triades.

Kidney damage was found in all PCB-treated animals, though with a wide individual variation. Hydropic degeneration (negative to PAS and Sudan black) of the convoluted 

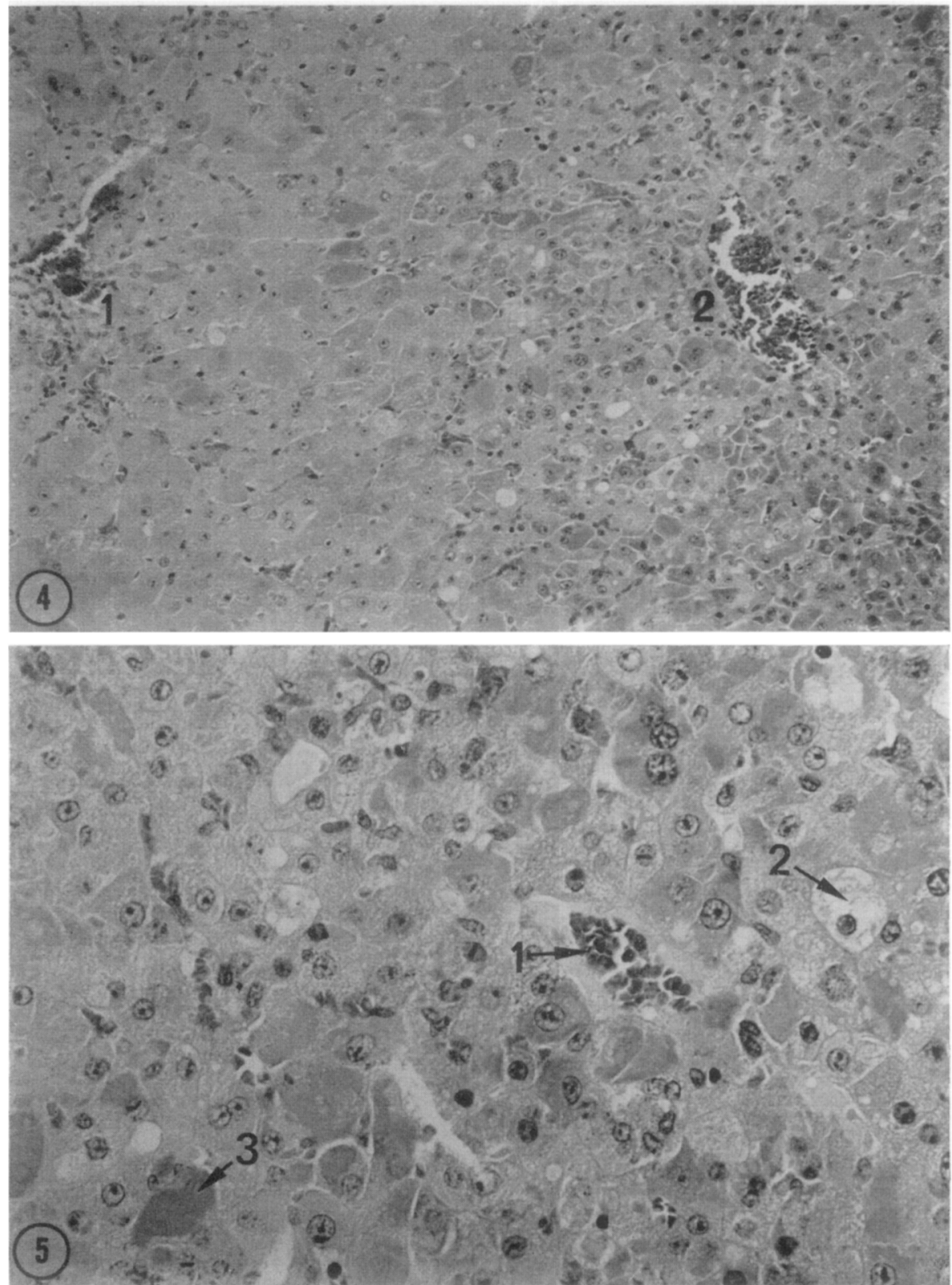

FIG. 4. Liver of a Clophen-treated rabhit that died after 31 days of treatment showing the portal triade at 1 , and degeneration and atrophy of the cytoplasm of the hepatocytes in the centrolobular area at 2 . Hematoxylin and eosin. $\times 150$.

FIG. 5. Higher magnification of the liver shown in Fig. 4. 1: central vein; $2:$ hydropic cell; 3 : focal cytoplasmic hyalin degeneration. Note also the enlarged nuclei and the karyopycnosis. Hematoxylin and eosin. $\times 375$. 


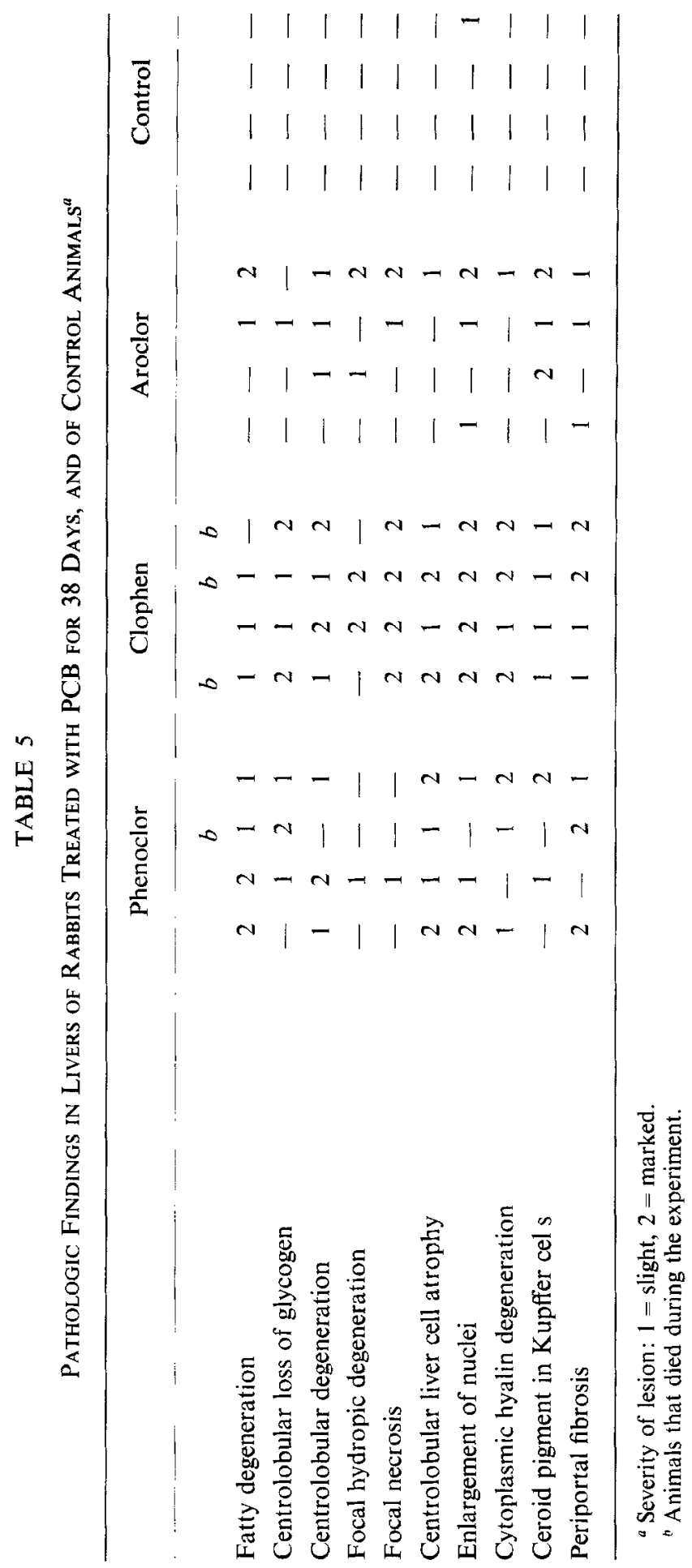


tubules (Fig. 6) was found in half of the animals. Nuclear pycnosis, rhexis, and lysis of the tubular epithelial cells were seen in all animals. Tubular dilatation, accompanied by the presence of casts of necrotic epithelial cells (Fig. 7), was found in half of the animals.
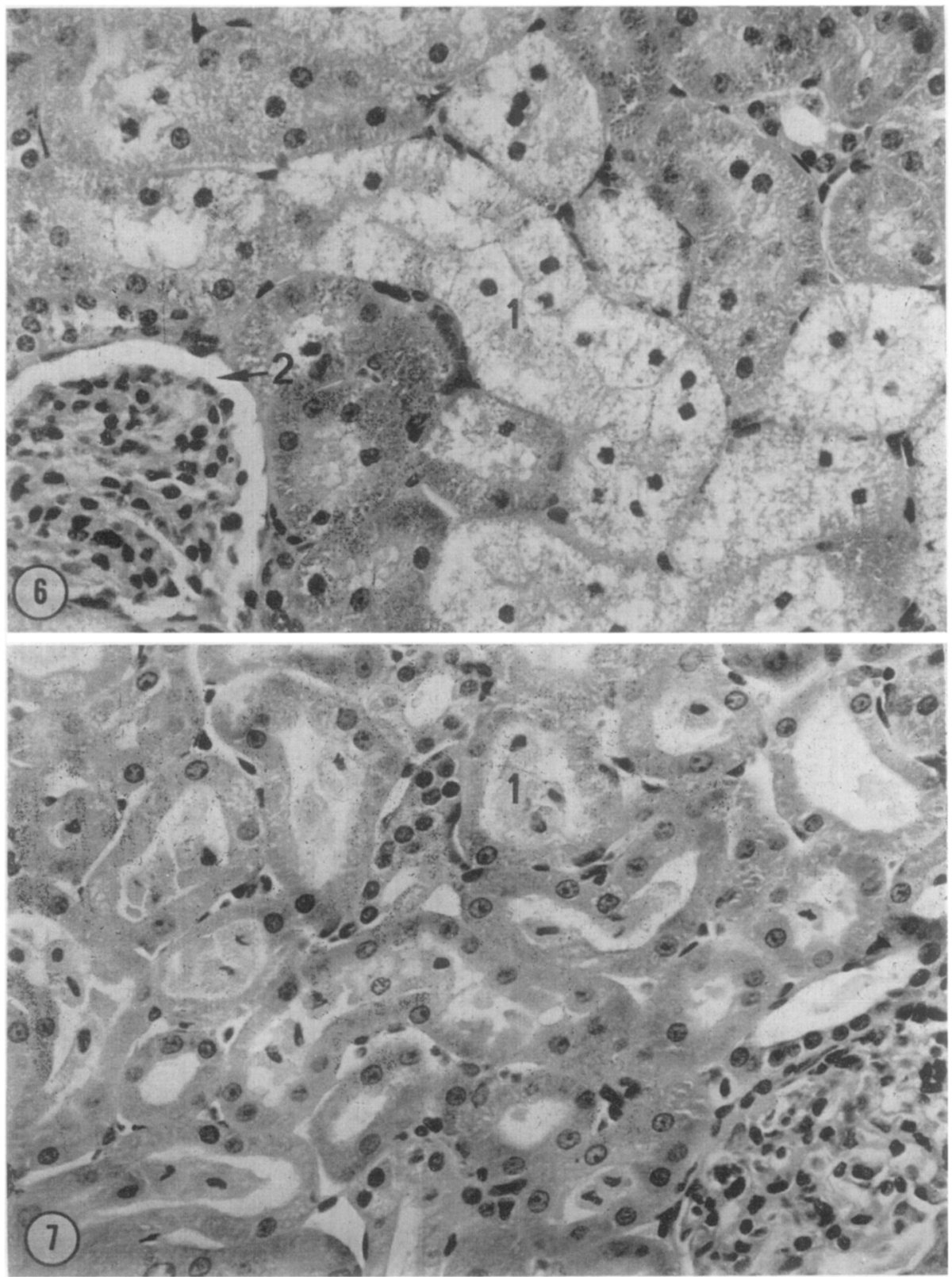

FIG. 6. Kidney of a killed rabbit from the Aroclor-treated group showing hydropic degeneration with nuclear pycnosis of the convoluted tubules (l). A slightly distended space of Bowman can also be seen (2). Hematoxylin and eosin. $\times 375$.

FIG. 7. Kidney section of the same animal as shown in Fig. 6, showing casts of necrotic epithelial cells in the tubules (I). Hematoxylin and eosin. $\rtimes 375$. 
TABLE 6

Diameter Measurements ( $\mu$ ) of Renal Corpuscles of Killed Rabbits Treated With PCB for 38 Days, and of Control Animals ${ }^{a}$

\begin{tabular}{|c|c|c|c|c|}
\hline & $N$ & $\begin{array}{c}\text { Capsule of } \\
\text { Bowman }\end{array}$ & Glomerulus & $\begin{array}{c}\text { Relative } \% \text { of the diameter } \\
\text { corresponding to the } \\
\text { space of Bowman }\end{array}$ \\
\hline Treated animals & 8 & $94.5(76.4-105.8)$ & $82.2(69.4-96.2)$ & $12.5(8.1-22.1)^{b}$ \\
\hline Controls & 4 & $91.5(86.0-96.5)$ & $85.2(79.4-90.4)$ & $6.5(5.0-7.9)$ \\
\hline
\end{tabular}

"Mean values; the range is shown in parentheses.

b Significantly different from controls, $P \leqslant 0.005$.

The tubular lesions explain the results of the diameter measurements of the renal corpuscles (Table 6).

Hemosiderin was found in the splenic macrophages of the test animals in larger quantities than in the controls. Moreover, a reduction in the number of germinal centers in the spleens as well as in the lymph nodes was found in the PCB groups. Atrophy of the cortex of the thymus was a common finding in the PCB-treated animals. No evidence of PCB-induced damage was found in the sections of the other organs.

\section{Experiment with the Diethylether-Hexane Fractions on the Ear Skin of Rabbits}

The four animals did not differ in weight gain during the lest period. After two weekly topical applications of the fraction from the 3 PCB samples, follicular keratosis was seen in both rabbits treated with the fraction of Phenoclor and Clophen. After 3 wk. when the animals were killed, the changes were more apparent (Fig. 8). The polar fraction of Aroclor did not give rise to gross changes.

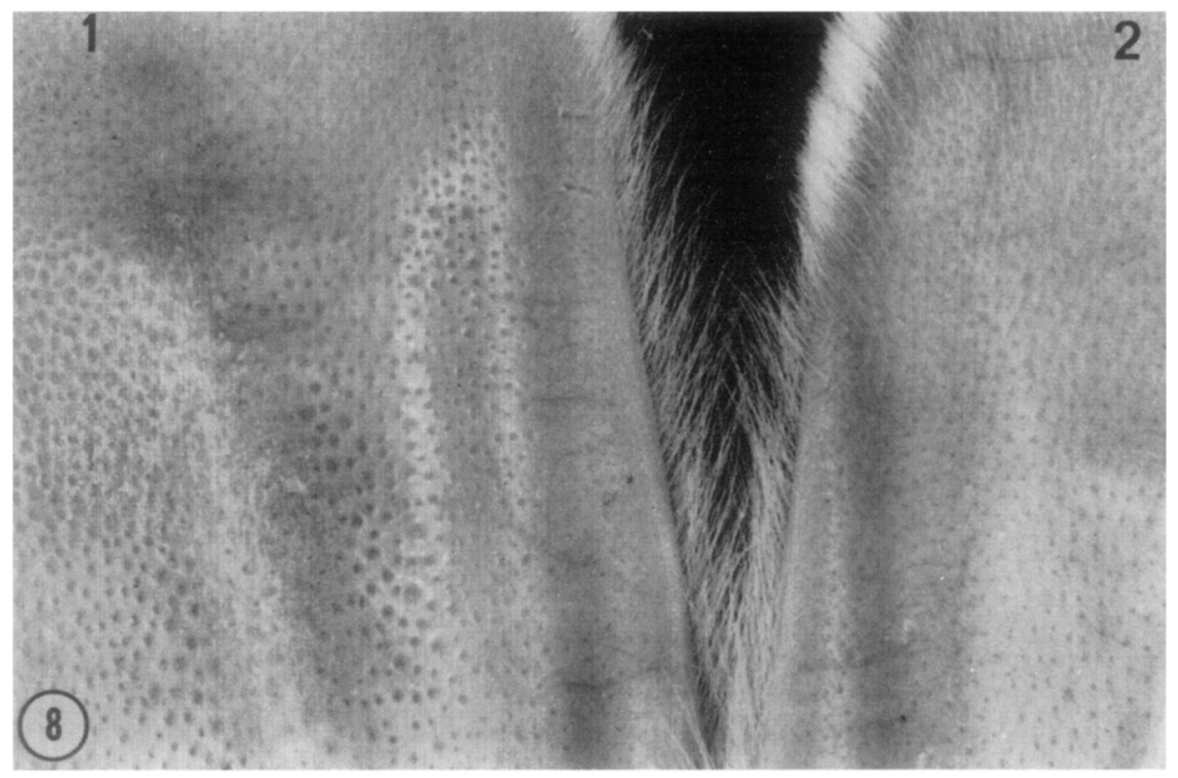

FIG. 8. Chloracne-like lesions on the inside of a rabbit's ear skin treated weekly, for 3 weeks, with the $25 \%$ diethylether in hexane fraction from Clophen. Note the follicular keratosis in the treated ear $(I)$ as compared with the control (2). 

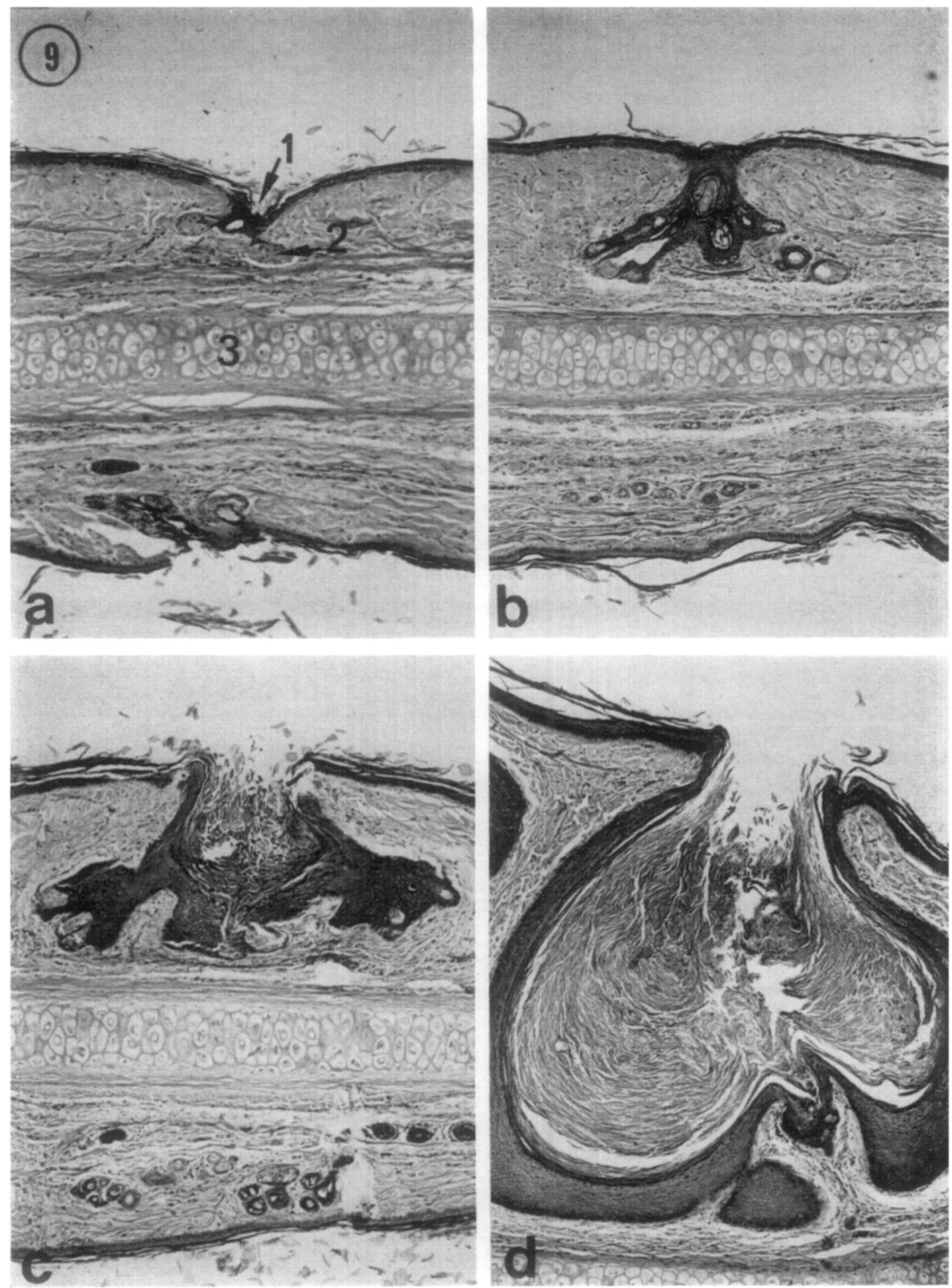

FIG. 9. Response of the inside of the rabbit's ear after topical application of the $25 \%$ diethyletherhexane fractions from technical polychlorinated biphenyls as seen in hematoxylin and eosin sections. 60 .

(a) Skin of control animal treated with ethanol. Note the hair follicle at 1, sebaceous gland tissue at 2 , and cartilage at 3. (b) Ear skin of the animal treated with the fraction from Aroclor. Some hyperplasia and hyperkeratosis of the follicular epithelium can be seen. (c) Ear skin of the rabbit treated with the fraction from Clophen. Considerable hyperplasia and hyperkeratosis of the follicular epithelium. (d) Ear skin of the rabbit treated with the fraction from Phenoclor. Part of a section that shows the most severe lesion. The gravity of the response was in general the same as seen in Fig. 9c. Note the cystic dilated hair follicle with prominent hyperplasia and hyperkeratosis of the follicular and epidermal epithelium. 
Histologically, hyperplasia and hyperkeratosis of the follicular epithelium with the presence of many keratohyalin granules (Fig. 10) were evident in the ear skin of animais treated with the Phenoclor and Clophen fractions (Fig. 9c and d). This comedolike formation was topically most pronounced in the rabbit treated with the Phenoclor fraction (Fig. 9d). Sebaceous gland tissue was decreased by treatment with both fractions (Fig. 10). Only mild hyperplasia and hyperkeratosis of the follicular epithelium was noted in the animal treated with the fraction of Aroclor (Fig. 9b). Hyperplasia and hyperkeratosis of the epidermal epithelium were also seen in the rabbits treated with the Phenoclor (Fig. 9d) and Clophen fractions but not in the animal treated with the Aroclor fraction.

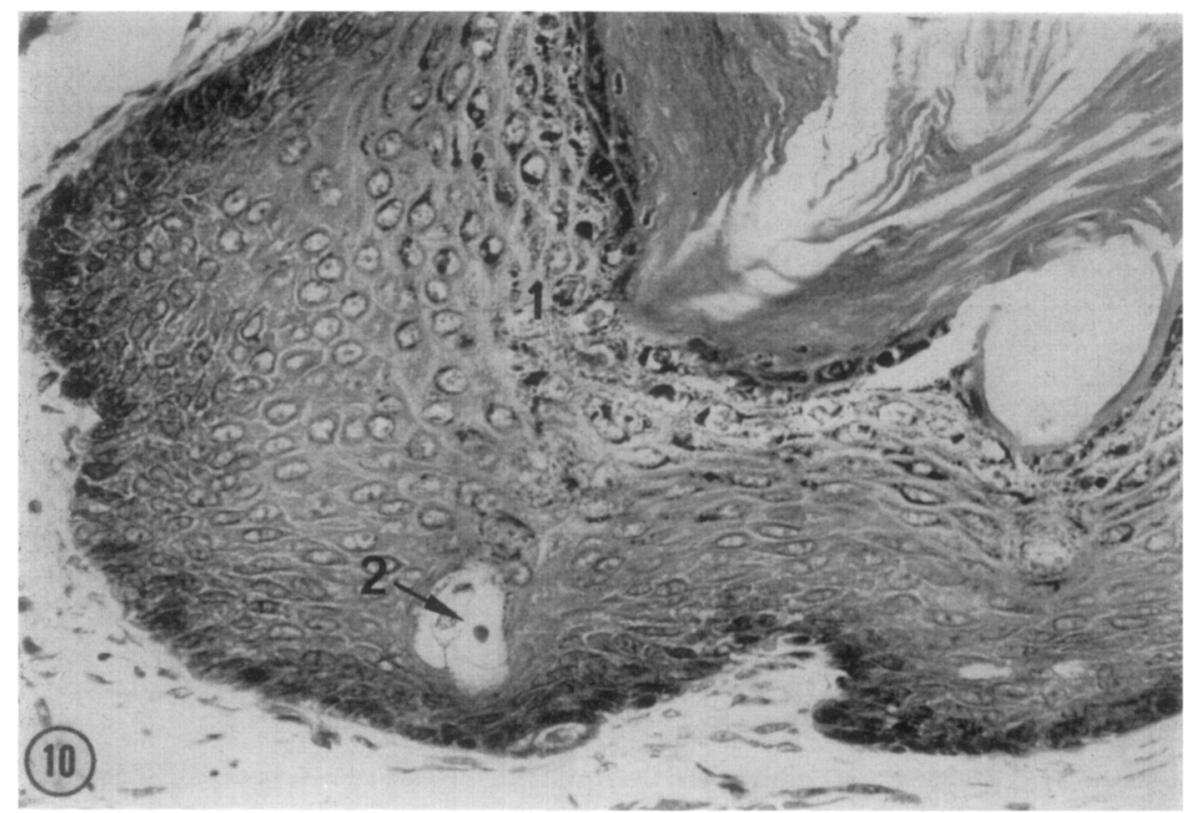

FIG. 10. Higher magnification of the ear skin shown in Fig. 9d. Hyperplasia and hyperkeratosis of the follicular epithelium with the presence of many keratohyalin granules $(l$ ). Note also a diminution (dedifferentiation) of the sebaceous gland tissue (2). Hematoxylin and eosin. $\times 375$.

No red fluorescence was recorded at examination of the total body and of liver sections in ultraviolet light. Liver sections of the test animals showed centrolobular vacuolisation, which stained positive with Sudan black.

\section{DISCUSSION}

An increase in fecal excretion of coproporphyrin and protoporphyrin induced by PCB is as readily established in the rabbit (Table 1 ) as in the chicken (Vos and Koeman, 1970). Absence of porphyria in animals treated with the toxic fractions indicates that PCB itself is porphyrogenic.

Liver and kidney lesions, except the loss of glycogen, the enlargement of nuclei, the ceroid deposits, the periportal fibrosis, and the dilatation of the space of Bowman, 
confirm the observations of Miller (1944). The lymphopenia (Table 3), the reduced number of germinal centers in the spleens and lymph nodes, the atrophy of the cortex of the thymus, and the atrophy of the white pulp and lymphoid foci found in the spleens of chicks fed PCB (Vos and Koeman, 1970) are strong indications for an immunosuppressive effect. This may need further study, particularly with regard to the extent to which these observations are due to stress (release of glucocorticoids).

It can be concluded that dermal application of PCB mixtures causes, besides the effect on the skin, systemic lesions of liver, kidneys, and lymphoid tissue.

From the response of the back skin and the liver of the rabbit to the 3 PCB mixtures, and from the response of the ear to the $25 \%$ diethylether-hexane fractions, it can be concluded that there are definite quantitative differences in toxicity, at least between the samples that were used in the present and the prior studies. The extent to which these samples are representative of the normal commercial output has not been studied. In a prior study (Vos et al., 1970), it appeared that the fraction of Clophen A60 was responsible for the toxicity of the PCB mixture, which also can be assumed to be true in the case of our samples of Phenoclor and Aroclor. From the response of the ear skin to the fractions it can be concluded that the presence of tetra- and pentachlorodibenzofuran in Clophen A60 and Phenoclor DP6, found by mass spectrometry (Vos et al., 1970), is definitely proved. The presence of a smaller quantity of toxic impurity in Aroclor, when compared with the Clophen and Plienoclor samples, is likely, considering the hydropericardium found in chicks fed with Aroclor (Flick et al., 1965) and also considering the present results. Preparation of pure PCB is therefore necessary for a comparative study. Uncontaminated PCB should be available.

These findings suggest that chloracne lesions induced by chlorinated naphthalenes and chick-edema-like lesions in chickens (Pudelkiewicz et al., 1959) may also be due to toxic impurities, as in the case of PCB's and chlorinated phenols (Bauer et al., 1961). Coal tar, which is an important source for naphthalene, may contain traces of dibenzofuran (Fieser and Fieser, 1956). Chlorination of technical naphthalene could then also produce chlorinated dibenzofuran.

Since PCB is a porphyrogenic chemical, it is possible that the skin lesions in man due to PCB are a combination of chloracne and acquired porphyria cutanea tarda. Bleiberg et al. (1964) found an etiologic relationship between the chloracne in workers engaged in the manufacture of dichlorophenol and trichlorophenol and acquired porphyria cutanea tarda.

From the present and prior studies (Vos and Koeman, 1970; Vos et al., 1970) it is concluded that it is important to take into account, in the evaluation of toxicity data of PCB, the possibility that PCB samples may differ in an important respect: the presence of toxic impurities. The interpretation of residue data in wildlife is very complicated for this reason.

\section{ACKNOWLEDGMENTS}

The authors are grateful to Mr. H. Baart de la Faille, dermatologist (Department of Dermatology, Hospital of the State University, Utrecht) and Dr. P. Kanaar, dermatologist (Department of Dermatology, Hospital of the State University, Leiden) for their help in the evaluation of the skin lesions. 


\section{REFERENCES}

Adams, E. M., IRISH, D. D., SPencer, H. C., and Rowe, V. K. (1941). The response of rabbit skin to compounds reported to have caused acneform dermatitis. Ind. Med., Ind. Hyg. Sect. $2,1-4$.

Bauer, H., Schulz, K. H., and Spiegelberg, U. (1961). Berufliche Vergiftungen bei der Herstellung von Chlorphenol-Verbindungen. Arch. Gewerbepathol. Gewerbehyg. 18, 538555 .

Венrвонм, P. (1959). Über Gefahren beim Umgang mit chlorierten Phenolen. Deut. Gesundheitsw. 14, 614-619.

Bennett, G. A., Drinker, C. K., and Warren, M. F. (1938). Morphologic changes in the livers of rats resulting from exposure to certain chlorinated hydrocarbons. J. Ind. Hyg. Toxicol. 20, 97-123.

Bleiberg, J., Wallen, M., Brodkin, R., and Applebaum, I. L. (1964). Industrially acquired porphyria. Arch. Dermatol. 89, 793-797.

Braun, W. (1955). Chlorakne, Monographien zur Zeitschrift "Berufsdermatosen." Band 1. Editio Canter, Aulendorff, Würtemberg, Germany.

Drinker, C. K., WARren, M. F., and BenNeTt, G. A. (1937). The problem of possible systemic effects from certain chlorinated hydrocarbons. J. Ind. Hyg. Toxicol. 19, 283-311.

DukE, T. W., LowE, J. I., and WILSON, A. J. (1970). A polychlorinated biphenyl (Aroclor 1254) in the water, sediment, and biota of Escambia Bay, Florida. Bull. Environ. Contamin. Toxicol. 5, $171-180$.

Fieser, L. F., and Fieser, M. (1956). Organic Chemistry, 3rd ed., pp. 527-531. Reinhold, New York.

Flick, D. F., O'Dell, R. G., and Childs, V. A. (1965). Studies of the chick edema disease. 3. Similarity of symptoms produced by chlorinated biphenyl. Poultry Sci. 44, 1460-1465.

Grefniurg, L., MaYers, M. R., and Smith, A. R. (1939). The systemic effects resulting from exposure to certain chlorinated hydrocarbons. J. Ind. Hyg. Toxicol. 21, 29-38.

HAMBRICK, G. W. (1957). The effect of substituted naphthalenes on the pilosebaceous apparatus of rabbit and man. J. Invest. Dermatol. 28, 89-103.

HofmanN, H. T. (1957). Neuere Erfahrungen mit hochtoxischen Chlorkohlenwasserstoffen. Naunyn-Schmiedebergs Arch. Exp. Pathol. Pharmakol. 232, 228-230.

Holden, A. V., and MarsDen, K. (1967). Organochlorine pesticides in seals and porpoises. Nature (London) 216, 1274-1276.

Holmes, D. C., Simmons, J. H., and Tatton, J. O'G. (1967). Chlorinated hydrocarbons in British wildlife. Nature (London) 216, 227-229.

JeNSEN, S. (1966). Report of a new chemical hazard. New Sci. 32, 612.

Jensen, S., Johnels, A. G., Olsson, M., and Otterlind, G. (1969). DDT and PCB in marine animals from Swedish waters. Nature (London) 224, 247-250.

Jones, J. W., and Alden, H. S. (1936). An acneform dermatergosis. Arch. Dermatol. Syphilol. 33, $1022-1034$.

Koeman, J. H., Oskamp, A. A. G., Veen, J., Brouwer, E., Rooth, J., Zwart, P., v. d. Broek, E., and VAN GENDEREN, H. (1967). Insecticides as a factor in the mortality of the sandwich tern (Sterna sandvicensis). Meded. Rijksfac. Landbouwwetensch. Gent 32, 841-854.

Koeman, J. H., Ten Noever de Brauw, M. C., and de Vos, R. H. (1969). Chlorinated biphenyls in fish, mussels and birds from the river Rhine and the Netherlands coastal area. Nature (London) 221, 1126-1128.

McCune, E. L., Savage, J. E., and O'Dell, B. L. (1962). Hydropericardium and ascites in chicks fed a chlorinated hydrocarbon. Poultry Sci. 41, 295-299.

MilleR, J. W. (1944). Pathologic changes in animals exposed to a commercial chlorinated diphenyl. Publ. Health Rep. 59, 1085-1093.

Porta, E. A., and Hartroft, W. S. (1969). Pigments in Pathology (M. Wolman, ed.), p. 210. Academic Press, New York.

Prestr, I., JefFeries, D. J., and Moore, N. W. (1970). Polychlorinated biphenyls in wild birds in Britain and their avian toxicity. Environ. Pollution 1, 3-26. 
Pudelkiewicz, W. J., Boucher, R. V., Callenbach, E. W., and Miller, R. C. (1959). Some physiological responses of New Hampshire chickens to a mixture of penta- and hexachloronaphthalenes. Poultry Sci. 38, 424-430.

Reitman, S., and Frankel, S. (1957). A colorimetric method for the determination of serum glutamic oxaloacetic and glutamic pyruvic transaminase. Amer. J. Clin. Pathol. 28, 56-63.

Rimington, C. (1961). Quantitative determination of porphobilinogen and porphyrins in urine and faeces. Broadsheet No. 36 of the Association of Clinical Pathologists. Copies may be obtained from Dr. R. B. H. Tierney, Pathology Laboratory, 75, Boutport Street, Barnstaple, Devon.

Risebrough, R. W., Rieche, P., Peakall, D. B., Herman, S. G., and Kirven, M. N. (1968). Polychlorinated biphenyls in the global ecosystem. Nature (London) 220, 1098-1102.

Schwartz, L. (1936). Dermatitis from synthetic resins and waxes. Amer. J. Publ. Health 26, 586-592.

Shelley, W. B., and Kligman, A. M. (1957). The experimental production of acne by pentaand hexachloronaphthalenes. A.M.A. Arch. Dermatol. 75, 689-695.

Strauss, N. (1944). Hepatotoxic effects following occupational exposure to Halowax (chlorinated hydrocarbons). Rev. Gastroenterol. 11, 381-396.

VAN DER WAERDEN, B. L. (1957). Mathematische Statistik, pp. 269-284. Springer, Berlin.

VON WedEL, H., Holla, W. A., and DentoN, J. (1943). Observations on the toxic effects resulting from exposure to chlorinated naphthalene and chlorinated phenyls with suggestions for prevention. Rubber Age (New York) 53, 419-426.

Vos, J. G., and Koeman, J. H. (1970). Comparative toxicologic study with polychlorinated biphenyls in chickens with special reference to porphyria, edema formation, liver necrosis, and tissue residues. Toxicol. Appl. Pharmacol., 17, 656-668.

Vos, J. G., Koeman, J. H., van der MaAs, H. L., Ten Noever de Brauw, M. C., and de Vos, R. H. (1970). Identification and toxicological evaluation of chlorinated dibenzofuran and chlorinated naphthalene in two commercial polychlorinated biphenyls. Food Cosmet. Toxicol. 8, 625-633. 